\title{
The impact of fibre processing on the mechanical properties of epoxy matrix composites and wood-based particleboard reinforced with hemp (Cannabis sativa L.)
} fibre

\author{
Albert Hernandez-Estrada ${ }^{1,2}$, Jörg Müssig ${ }^{3}$, and Mark Hughes ${ }^{1, \star}$ (1) \\ ${ }^{1}$ Department of Bioproducts and Biosystems, Aalto University School of Chemical Engineering, P.O. Box 16300, 00076 Aalto, \\ Finland \\ ${ }^{2}$ Department of Post-Harvest Technology, Leibniz Institute for Agricultural Engineering and Bioeconomy (ATB), Max-Eyth-Allee 100, \\ 14469 Potsdam, Germany \\ ${ }^{3}$ HSB - Hochschule Bremen, City University of Applied Sciences, Faculty 5, Biomimetics-The Biological Materials Group, \\ Neustadtswall 30, 28199 Bremen, Germany
}

Received: 20 August 2021

Accepted: 11 October 2021

Published online:

3 January 2022

(C) The Author(s) 2021

\begin{abstract}
This work investigated the impact that the processing of hemp (C. sativa L.) fibre has on the mechanical properties of unidirectional fibre-reinforced epoxy resin composites loaded in axial tension, and particleboard reinforced with aligned fibre bundles applied to one surface of the panel. For this purpose, mechanically processed (decorticated) and un-processed hemp fibre bundles, obtained from retted and un-retted hemp stems, were utilised. The results clearly show the impact of fibre reinforcement in both materials. Epoxy composites reinforced with processed hemp exhibited 3.3 times greater tensile strength when compared to the un-reinforced polymer, while for the particleboards, the bending strength obtained in those reinforced with processed hemp was 1.7 times greater than the un-reinforced particleboards. Moreover, whether the fibre bundles were processed or un-processed also affected the mechanical performance, especially in the epoxy composites. For example, the un-processed fibre-reinforced epoxy composites exhibited $49 \%$ greater work of fracture than the composites reinforced with processed hemp. In the wood-based particleboards, however, the difference was not significant. Additionally, observations of the fracture zone of the specimens showed different failure characteristics depending on whether the composites were reinforced with processed or unprocessed hemp. Both epoxy composites and wood-based particleboards reinforced with un-processed hemp exhibited fibre reinforcement apparently able to
\end{abstract}

Handling Editor: Stephen Eichhorn.

Address correspondence to E-mail: mark.hughes@aalto.fi

E-mail Addresses: ahernandez@atb-potsdam.de; jmuessig@bionik.hs-bremen.de 
retain structural integrity after the composite's failure. On the other hand, when processed hemp was used as reinforcement, fibre bundles showed a clear cut across the specimen, with the fibre-reinforcement mainly failing at the composite's fracture zone.

\section{Introduction}

Interest in using natural fibres to reinforce composites has resulted in the development of a range of fibre-reinforced polymers [1-4] that use fibres from plants like flax and hemp, to substitute human-made alternatives such as glass fibres (e.g. [5, 6].). The wide range of possible uses for these fibres (e.g. [7, 8].) is partially responsible for this growing interest, and, in addition to applications in natural fibre-reinforced polymers (NFRPs) (e.g. [7, 8].), there has been research conducted on the reinforcement of other materials such as concrete (e.g. [9, 10].) and plaster (e.g. [11].). In the form of NFRPs, the high strength and stiffness of bast fibres [12-15] can be harnessed to reinforce wood products like timber [16] and particleboard [17]. This could potentially create new application areas for wood-based products as well as developing new markets for natural fibres.

The high strength and stiffness often quoted for bast fibres $[12,18,19]$ is, however, seldom realised in practice due to fibre damage caused during its extraction from the straw; this damage can negatively affect the properties of NFRPs [13] and, by extension, most probably on wood-based panels reinforced with them. The aims of the work reported in this paper were, therefore, twofold: firstly, to study how fibre damage affects the properties of NFRPs and, secondly, to explore the potential for hemp fibre to reinforce particleboard, thereby enhancing its mechanical properties and, potentially, increasing its value.

\section{Dislocations in bast fibres and impact on mechanical properties}

In production, the outermost layer of the stem-the bast-is first removed from the woody core. The coarse bast can then be separated into finer fibre bundles, which in length can be as long as the stem itself. Through further processes, a fibre bundle can be subsequently separated to yield single fibres, which in the case of hemp can be 5-55 mm long [4]. Figure 1 shows the different degrees of intensive separation from fibre bundles to single fibres for the bast fibre plant, flax.

The process of isolating fibres from the plant stem involves mechanical action, which damages the fibres. This damage takes the form of cell wall "kinks" $[13,20-22]$ and is due to misorientation of the microfibrils in the $S_{2}$ layer of the secondary cell wall $[23,24]$. These damaged regions of misoriented microfibrils are often termed dislocations [25] and may be seen under polarised light [26, 27]. In cases where the deformation affects the entire cell, they can be observed using scanning electron microscopy (SEM) $[28,29]$ or optical microscopy $[28,30]$.

Different processing steps produce varying amounts of dislocations. Hernandez-Estrada et al. [31], for example, reported that initial processing (i.e. decortication) produces the largest number of dislocations in the fibre structure, although subsequent processing, (e.g. refining to separate the fibre bundles from the bast), adds to this. Hänninen et al. [21] suggest that there is a "saturation level", in terms of the number of dislocations that can be produced in the fibre.

It has been noted that dislocations can affect the properties of bast fibres when they are loaded in tension along the axis of the fibre [13]. For example, it has been reported that in flax [18] and hemp [12] dislocations cause failure, which, as noted by both Baley [32] and Bos et al. [28], generally takes place nearby the dislocations. Likewise, Aslan et al. [33] noted that failure in single flax fibres started near the dislocations, which was followed by splitting lengthwise, causing total failure when the split reached the next dislocation in the fibre.

Another feature of bast fibres is that when they are loaded in axial tension, the force-deformation history displays characteristic nonlinearity [34, 35]. This behaviour has been attributed to the microfibrils rotating, and progressively realigning with the fibre axis, as well as the viscoelastic characteristics of the cell wall [36, 37]. This has been experimentally 
Figure 1 Scanning electron micrographs of flax fibre bundles with different thicknesses and a single fibre in front (upper image).

a Scanning electron micrograph of dislocations in a flax fibre bundle. $b$ Schematic representation of dislocations in a flax fibre bundle. c Dislocations in flax, shown as bright zones crossing the fibre when viewed under polarised light in an optical microscope (adapted and modified from Müssig and Hughes [14]).

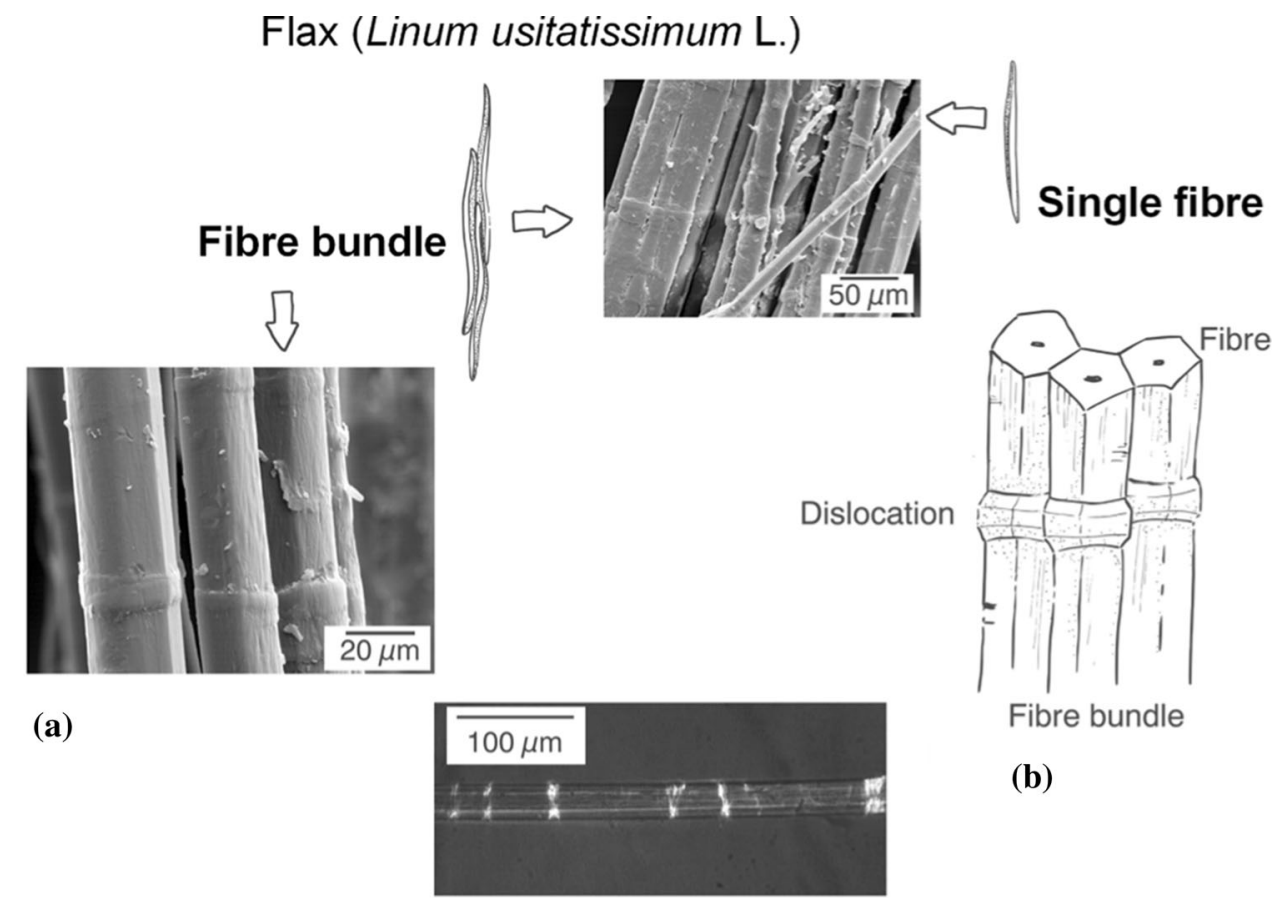

(c) verified by Thygesen et al. [23] and Placet et al. [35] who noted that when fibres are loaded in axial tension under polarised light, the dislocations gradually disappear, suggesting that re-alignment of the microfibrils along the axis of the fibre occurs.

\section{Bast fibres as reinforcement in composite materials}

When fibres reinforce polymer matrix composites, the dislocations, in effect, create regions of higher strain in the fibre $[30,38]$ that can potentially result in interfacial failure [30]. Observations by Rask et al. [39], using synchrotron X-ray tomographic microscopy, show that the failure of the fibre-reinforcement of a hemp yarn fibre-reinforced polypropylene composite starts at the dislocations, confirming the findings of Hughes et al. [30]. When used as composite reinforcement, both hemp and flax exhibit other types of damage, like splitting at the fibre bundle level, damage at the fibre-matrix interface and splitting within single fibres in the longitudinal direction $[39,40]$. These types of failure have also been observed at the fibre bundle level for hemp [41] and flax [33] tested in axial tension.

\section{Bast fibres reinforcing wood-based products}

Natural fibres have also been used to reinforce woodbased products, for example, in the form of woven textiles to reinforce formable compressed wood [42], or in particleboard reinforced with hemp and flax fibres [17] or sugarcane bagasse [43]. In the field of wood-based panels, Sam-Brew and Smith [17] used aligned flax and hemp fibres to reinforce particleboard as a sub-layer below the panels' external surfaces. Fibres were aligned using a carding board and a hand carder to form webs $3 \mathrm{~mm}$ thick. They showed that hemp fibre-reinforced wood particleboard had $53 \%$ higher bending modulus of rupture and $32 \%$ higher bending modulus of elasticity than the un-reinforced, $100 \%$ wood, panels.

In more demanding applications, such as reinforcing wooden beams, some studies report the use of natural fibres in the form of NFRP components attached to the beams (e.g. [16, 44, 45]. André and Johnsson [44], for example, attached a NFRP flax fibre-epoxy composites to a glue-laminated wooden beam, reinforcing the transverse tensile properties, and obtained a $74 \%$ higher transverse tensile strength (i.e. perpendicular to the grain) in the reinforced beams when compared to un-reinforced beams.

Similarly, Borri et al. [16] used different configurations of flax and hemp-reinforced polymer matrix 
composites though, in this case, attaching the NFRP components parallel to the axial direction of the wooden beam. In four-point bending tests, it was clearly shown that the beams reinforced with the NFRP elements exhibited better mechanical performance compared to the un-reinforced beams. For example, wooden specimens reinforced with one layer of a bidirectional hemp fibre-reinforced polymer element had a bending strength $24 \%$ higher than the un-reinforced specimens [16]. When the same wooden beams were reinforced with unidirectional flax fibre-reinforced composites, the bending strength was $35.4 \%$ higher than the un-reinforced wooden specimens [16], which clearly indicates improved mechanical performance when NFRP composite elements are attached to a wooden beam.

\section{Objectives}

Bast fibres have good potential to reinforce other materials, such as polymers, although it is not known to what extent fibre dislocations affect the strength and behaviour of such materials. The aim of this work was, therefore, to investigate the impact that dislocations have on the ability of hemp fibre to act as reinforcement, firstly in a unidirectional fibre-reinforced epoxy composite tested in axial tension and secondly in wood-based particleboard reinforced with fibres attached to one surface of the board and tested in three-point bending, with the fibres reinforcing the tension surface. To do this, the composites were reinforced with either mechanically processed (decorticated) fibre bundles that were likely to contain a significant number of dislocations, or fibre bundles that had been carefully extracted manually from the stem to minimise the occurrence of dislocations.

\section{Materials and methods}

\section{Raw materials and processing}

The fibre bundles used in this work were from hemp (USO-31 variety) that was grown in 2012 in Potsdam, Germany. After manual harvesting, a proportion of stems was dew-retted, and the remainder dried without retting. Some of the dew-retted (DR), as well as un-retted (UR) stems, were mechanically decorticated (DE) by passing them three times through a decorticator (Worthmann Maschinenbau $\mathrm{GmbH}$, Barßel-Harkebrügge, Germany) to isolate the fibre from the stem (DR-DE and UR-DE, respectively, in Fig. 2). For an overview of how the fibre was processed and a detailed description of the equipment used to decorticate the straw, the reader is directed to Hernandez-Estrada et al. [31] and Wang et al. [46], respectively.

In order to minimise mechanical damage to the fibres, dew retted and un-retted fibre bundles (DRPD and UR-PD, respectively, in Fig. 2) were manually separated from strips of bast, approximately $300 \mathrm{~mm}$ long, by cutting lengthwise with a razor blade. These were used in the subsequent production of composites and reinforced particleboard (see below), and the decorticated hemp was used as was, following decortication. The term 'hemp' is used in the following for a collection of fibre bundles from the bast fibre plant hemp, Cannabis sativa L. Figure 2 shows the processing that the hemp underwent and the subsequent formation of composites reinforced with these fibres and the particleboard reinforced with each fibre type.

\section{Fibre-reinforced epoxy resin composites}

As shown in Fig. 2, two sets of fibre-reinforced epoxy composites (FRC) were produced. FRC-PD composites were reinforced with un-retted, un-processed hemp (UR-PD) with a width of $0.72 \mathrm{~mm} \pm 0.27 \mathrm{~mm}$ (mean and standard deviation of 95 measured fibre bundles) and FRC-DE composites had un-retted, decorticated hemp (UR-DE) as a reinforcement with a width of $0.20 \mathrm{~mm} \pm 0.11 \mathrm{~mm}$ (mean and standard deviation of 90 measured fibre bundles). The third set of specimens was produced in this part (FRC-REF) that were of un-reinforced resin. The fibre bundles used as reinforcement in the FRC-PD and FRC-DE composites were sampled randomly to use fibres from stems of different origin. The fibre volume fraction was set to $30 \%$ and was estimated by weighing the fibre bundles with a length of $60 \mathrm{~mm}$ (see Fig. 3), assuming a density of $1500 \mathrm{~kg} \mathrm{~m}^{-3}$ [47, 48].

The matrix used was Epikote MGS RIMR135 epoxy resin with Epikure MGS RIMH137 curing agent, both manufactured by Lange + Ritter (Gerlingen, Germany). The mixture for the matrix was produced with a 100:30 (w/w) ratio of resin/curing agent, hereinafter referred to as "resin". The mould used to 


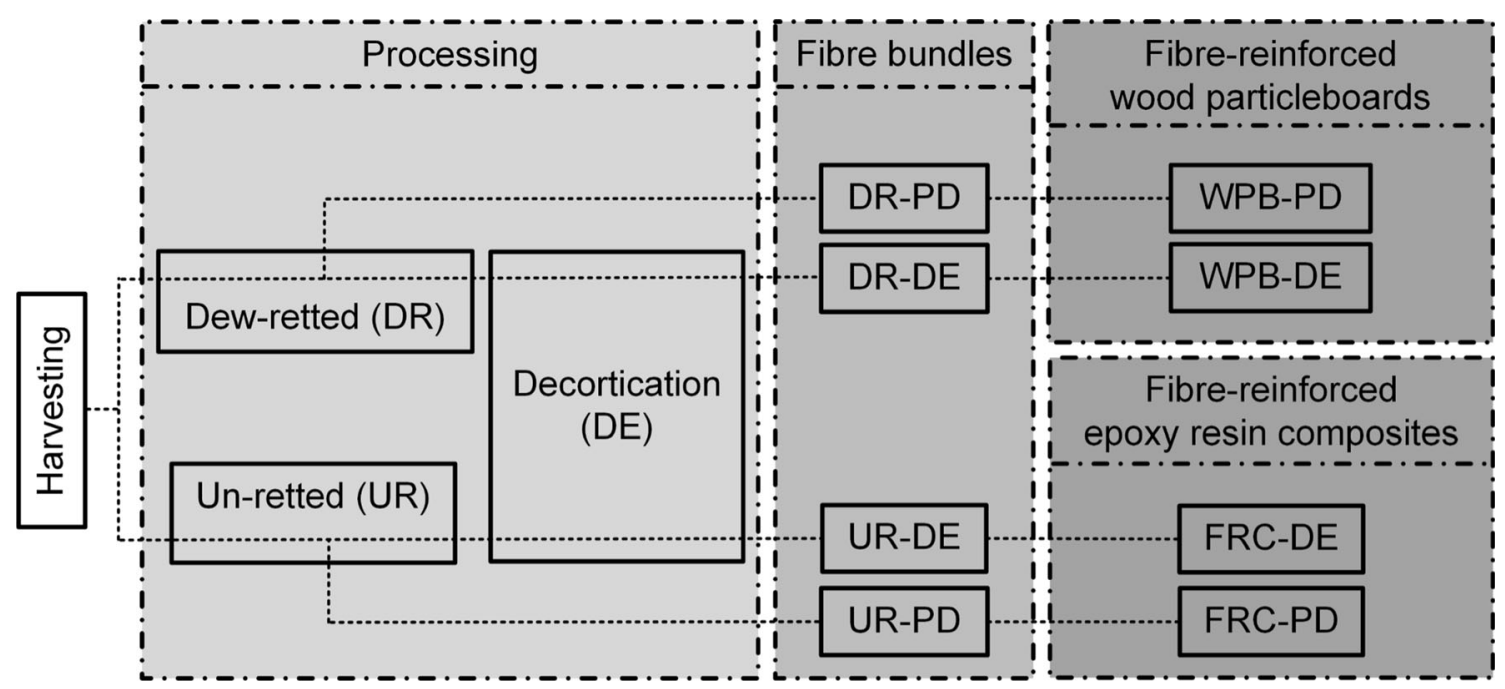

Figure 2 Processing that the harvested hemp stems underwent to produce the fibre bundles used in this work, and the respective products. DR-PD: Dew-retted hemp prior to decortication; DRDE: Dew-retted, decorticated hemp; UR-PD: Un-retted hemp prior to decortication; UR-DE: Un-retted, decorticated hemp; WPB-PD:
Wood-based particleboard reinforced with DR-PD hemp; WPBDE: Wood-based particleboard reinforced with DR-DE hemp; FRC-PD: Epoxy resin composite fibre-reinforced with UR-PD hemp; FRC-DE: Epoxy resin composite fibre-reinforced with URDE hemp.

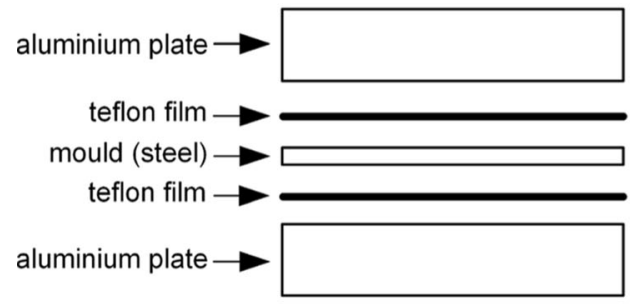

(a)

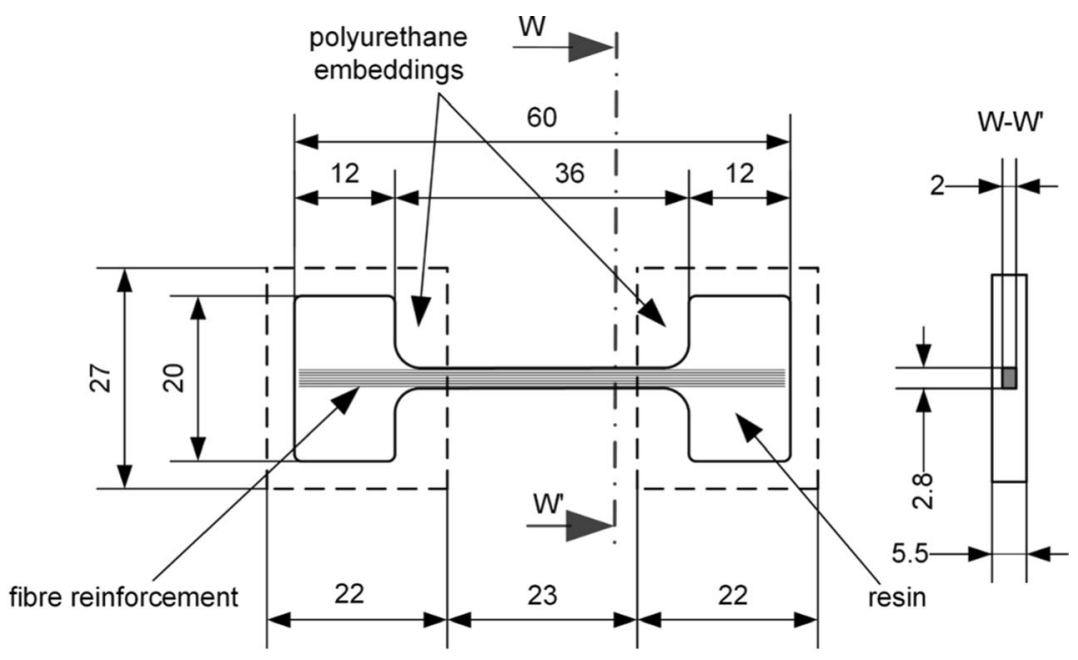

(b)

Figure 3 a Set-up used in this work to produce the hemp fibre-reinforced epoxy resin composites. b Schematic of the hemp fibrereinforced epoxy resin composite specimens produced in this work. Dimensions in $\mathrm{mm}$.

produce the composites consisted of two thick aluminium plates with a thin steel plate in between that had the specimen shape cut out (Fig. 3a). Thin Teflon sheets were used between the metallic plates to facilitate demoulding of the composite specimens (Fig. 3a), and wax (04.01A.K1, Lange + Ritter, Gerlingen, Germany) was also applied to the metal surfaces for the same reason.

The fibre bundles were dried for $18 \mathrm{~h}$ at $60{ }^{\circ} \mathrm{C}$ in a climate-controlled chamber with forced air (Vötsch
VCL 4003, Vötsch Industrietechnik $\mathrm{GmbH}$, Reiskirchen-Lindenstruth, Germany), and the mass required to reinforce each composite specimen was measured in these conditions. Following this, the fibre-reinforcements were first pre-soaked in resin for $10 \mathrm{~min}$ and, thereafter, placed in the mould where additional resin was added to fill the specimen shape (Fig. 3b). The mould was then sealed with clamps and left under a fume hood at room temperature for $48 \mathrm{~h}$ to cure the resin. After demoulding, the 
specimen edges were polished first with P180 and then with P2000 grit sandpaper. Fast-curing twocomponent polyurethane resin (TFC PU 2031, Troll Factory, Riede, Germany) was then used, with the help of a 3D-printed mould, to embed both ends of each specimen (Fig. $3 b$ ) to enable the specimens to be gripped better during testing. A ratio of $1: 1(\mathrm{w} / \mathrm{w})$ was used for the two components comprising the polyurethane resin. After the polyurethane was cured, the specimens were post-cured for $18 \mathrm{~h}$ at $60{ }^{\circ} \mathrm{C}$ in the aforementioned climate-controlled chamber.

Before testing, the specimens were conditioned for $24 \mathrm{~h}$, using the same climate-controlled chamber, in this case set at $23{ }^{\circ} \mathrm{C}$ and $50 \%$ relative humidity (RH). The tensile tests were carried out using a calibrated Zwick/Roell Z020 (Ulm, Germany) universal tester fitted with a $20 \mathrm{kN}$ load cell. The testing speed was $2 \mathrm{~mm} \mathrm{~min}{ }^{-1}$, and testing continued until failure of the specimen. The cross-sectional area was calculated from the dimensions in the specimen's gauge length (23 mm in Fig. 3b). Three measurements of width and thickness were made in this region, and the mean value was used to calculate the cross section and, together with the load measurements, stress and tensile strength ( $\sigma_{\mathrm{FRC}}$ in Fig. 4a).

For each stress-strain curve, Young's modulus ( $E_{\mathrm{FRC}}$ in Fig. $4 \mathrm{a}$ ) was determined by linear regression of the stress-strain data between $1.5-5 \mathrm{MPa}$. The

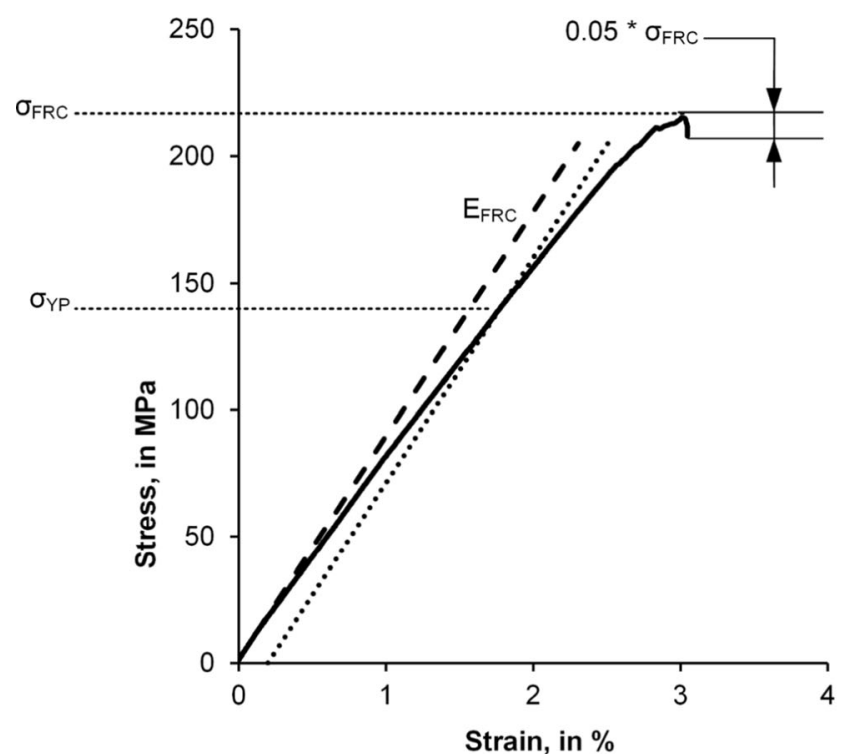

(a) strain was calculated using the crosshead displacement and the initial gauge length (23 mm in Fig. 3b). The compliance of the set-up was not taken into account. In this work, failure of the specimen and, thus, the end of the stress-strain curve was considered to be the point at which tensile stress decreased by more than $5 \%$ from the maximum stress $\left(\sigma_{\mathrm{FRC}}\right.$ in Fig. 4a). Failure strain ( $\varepsilon_{\mathrm{FRC}}$ in Fig. 4a) was set accordingly.

For each stress-strain curve, a line, parallel to the Young's modulus and crossing the abscissa at $0.2 \%$ strain, was plotted to determine the yield point $\left(\sigma_{\mathrm{YP}}\right.$ in Fig. 4a). If the $0.2 \%$-strain line did not intersect with the stress-strain curve, the test was considered to be linear, whereas if the $0.2 \%$-strain line did intersect, the test was considered to exhibit nonlinear behaviour and, therefore, a 'yield point' was determined at the point of intersection ( $\sigma_{Y P}$ in Fig. 4a). The classification of the stress-strain curves enabled a comparison to be made between the different sets of fibre-reinforced epoxy composites produced in this work and, consequently, an analysis of the impact of fibre processing on their mechanical behaviour.

\section{Work of fracture of epoxy resin composites}

The work of fracture reported herein (work $\mathrm{FRC}_{\mathrm{FR}}$ ) was calculated from the area below the load-displacement curve (load in $\mathrm{N}$; displacement in $\mathrm{m}$ ), from the

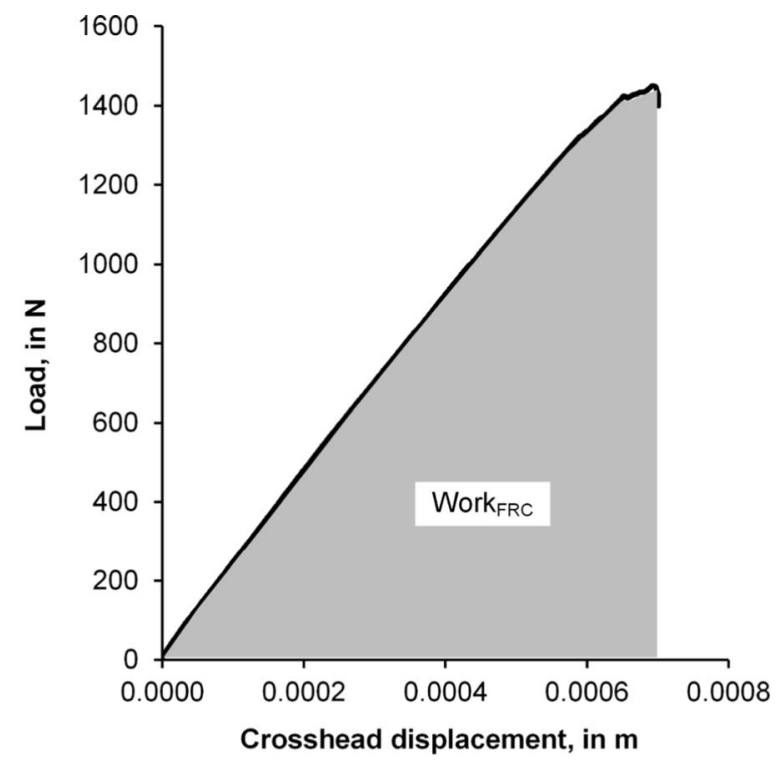

(b)

Figure 4 a Stress-strain response exhibited by a fibre-reinforced epoxy resin composite specimen. b Load-displacement curve of a fibrereinforced epoxy resin composite specimen used to calculate the work of fracture (work FRC $_{\text {) }}$. 
beginning of the curve to the failure of the specimen (see Fig. 4b), divided by the nominal cross section of the epoxy composite (detail W-W' in Fig. 3b), and it is reported in this work in $\mathrm{kJ} \mathrm{m}^{-2}$.

\section{Hemp fibre-reinforced particleboard}

Untreated and uncoated commercial particleboard, with a nominal thickness of $11 \mathrm{~mm}$ (board density $700 \mathrm{~kg} \mathrm{~m}^{-3}$ ), was machined into $120 \mathrm{~mm} \times 20 \mathrm{~mm}$ specimens (Fig. 5a). Un-processed and processed, dew-retted hemp (DR-PD and DR-DE, respectively, in Fig. 2), conditioned at $20^{\circ} \mathrm{C}$ and $\mathrm{RH} 65 \%$, was used to reinforce the particleboard, herein termed WPB-PD and WPB-DE, respectively (Fig. 2). The width of DR-PD and DR-DE was $0.77 \mathrm{~mm} \pm 0.29$ $\mathrm{mm}$ and $0.10 \mathrm{~mm} \pm 0.07 \mathrm{~mm}$, respectively (mean and standard deviation for 101 and 78 measured fibre bundles, respectively). Un-reinforced particleboard (WPB-REF) was used as a reference.

Each particleboard specimen was reinforced with $100 \mathrm{mg} \pm 5 \mathrm{mg}$ of aligned and conditioned hemp fibre bundles (Fig. 2) cut to a length of $120 \mathrm{~mm}$. The fibre bundles were glued on one surface of the particleboard specimen (Fig. 5a) using cyanoacrylate adhesive (Bison International B.V., Goes, The Netherlands), which was also used as a binder to keep the fibre bundles together. The adhesive was applied such that it formed a continuous matrix around the fibres (Fig. 5a). The adhesive was cured in a fume hood at room temperature, and, thereafter, the specimens were conditioned at $20{ }^{\circ} \mathrm{C}$ and $\mathrm{RH} 65 \%$ for a minimum of one week prior to testing.
The reinforced particleboards were tested in threepoint bending with the fibre-reinforcement on the tension side (Fig. 5b) using a method based on EN 310:1993 [49]; in this work, the set-up was adapted to the dimensions of the specimens (Fig. 5b). Testing was carried out at $20^{\circ} \mathrm{C}$ and $\mathrm{RH} 65 \%$ using a calibrated Zwick 1475 (Ulm, Germany) universal tester, using a $1 \mathrm{kN}$ load cell. The test speed was set to $2 \mathrm{~mm} \mathrm{~min}{ }^{-1}$, and the specimens were loaded to failure, which was considered to be the point at which the load decreased by more than $5 \%$ below the maximum load. Modulus of elasticity in bending and bending strength ( $E_{\mathrm{WPB}}$ and $\sigma_{\mathrm{WPB}}$, respectively) was calculated according to EN 310:1993 [49].

\section{Work of fracture of particleboards}

In addition, the work of fracture (herein work $\mathrm{WPB}_{\mathrm{WPB}}$ ) of the un-reinforced and fibre-reinforced particleboards was calculated as the area below the load-displacement curve (load in N; crosshead displacement in $\mathrm{m}$ ) from the beginning of the curve to failure of the specimen (see Fig. 6), and further divided by the nominal specimen's cross section ( $t$ and $w$ in Fig. 5a), and it is herein reported in $\mathrm{kJ} \mathrm{m}^{-2}$.

\section{Statistical analysis}

Results of the mechanical tests reported in this work were analysed statistically (ANOVA and $t$-test) with a confidence level of 95\%, using the add-in Analysis ToolPak of Microsoft Excel.

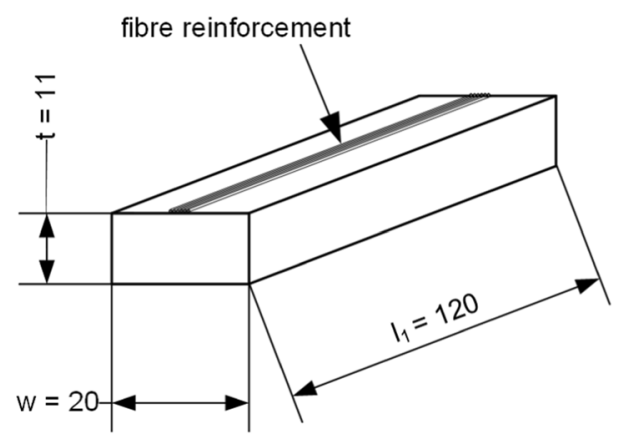

(a)

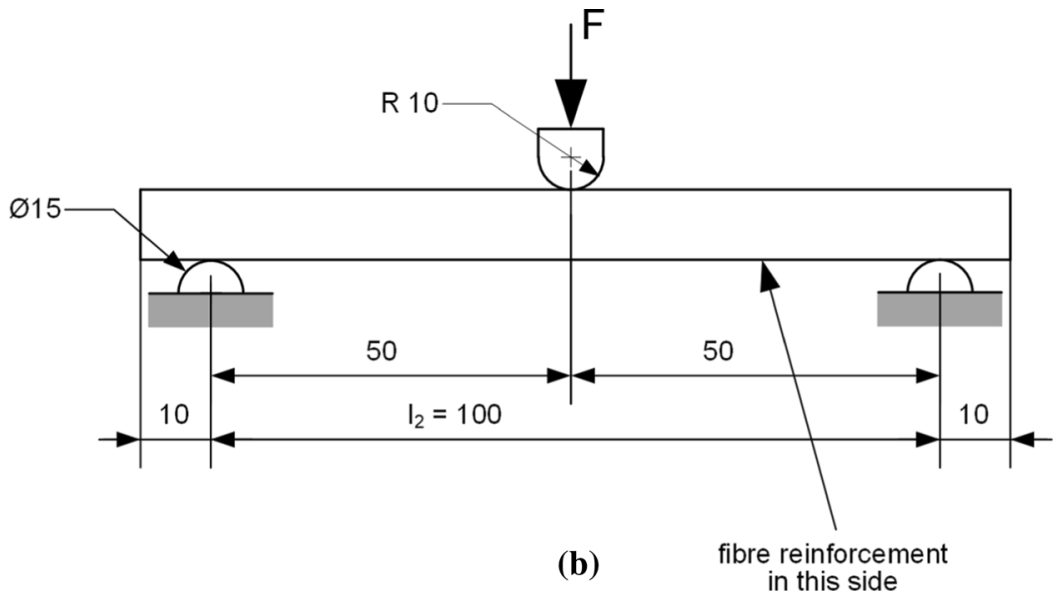

(b)

$$
\text { in this side }
$$

Figure 5 a Schematic of the wood-based particleboard reinforced with hemp produced in this work. $\mathbf{b}$ Three-point bending set-up used to test the wood-based particleboards. Dimensions in mm. 


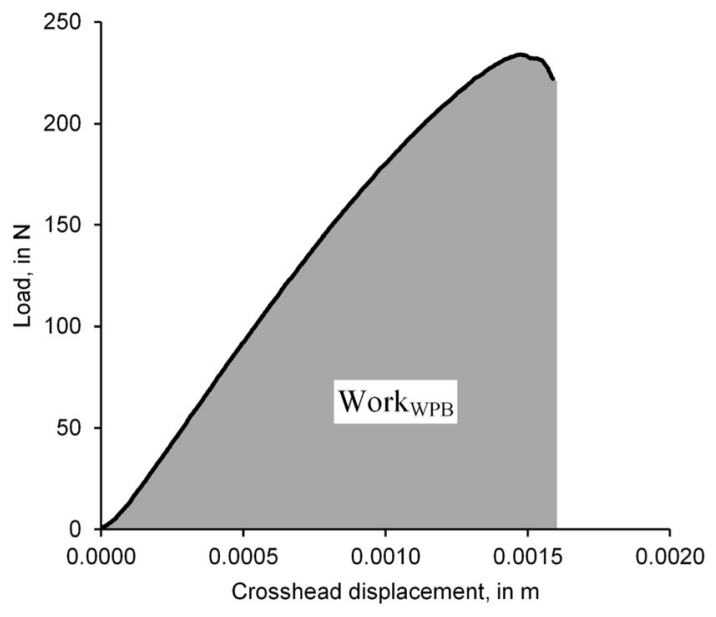

Figure 6 Load-displacement curve of a particleboard showing the area under the curve, used to calculate the work of fracture ( work $_{\mathrm{WPB}}$ ).

\section{Results and discussion}

\section{Hemp fibre-reinforced epoxy resin composites}

Table 1 summarises the mechanical properties of the three sets of epoxy resin composite specimens. As may be seen from the table, the pure epoxy resin (FRC-REF) exhibited an average tensile strength of 46.76 MPa and Young's modulus of 1.87 GPa. These values are clearly at the lower end of the spectrum of values reported in the literature for epoxy resin, i.e. 30-100 MPa and 1.76-10 GPa, respectively, for the tensile strength and modulus of elasticity $[16,50,51]$. For Young's modulus, this difference could be attributable to the fact that strain was measured indirectly through crosshead movement, so inaccuracies in strain measurement could have arisen from not taking into account the set-up compliance.
However, this is not problematic for comparative purposes. Moreover, since the epoxy composites were produced without vacuum degassing, microbubbles present in the resin might have contributed to reducing both the tensile strength and modulus of elasticity.

An ANOVA test performed on the results of the mechanical tests in the three specimen groups (FRCREF, FRC-PD and FRC-DE in Table 1), showed that the results of the three groups are statistically different at a confidence level of $95 \%$, for all the mechanical properties shown in Table 1. Moreover, $t$ tests carried out on the results of the FRC-PD and FRC-DE specimens showed that both sets of results are significantly different for the tensile strength, Young's modulus, work and yield point $\left(\sigma_{\mathrm{YP}}\right)$, shown in Table 1. However, the t-test carried out on the results of maximum strain $\left(\varepsilon_{\mathrm{FRC}}\right.$ in Table 1$)$ indicated that the two means $(2.79 \%$ and $2.61 \%$ for FRC-PD and FRC-DE, respectively, in Table 1) are not significantly different at a confidence level of $95 \%$.

In detail, concentrating on the differences between the two sets of epoxy composites reinforced with unprocessed and processed hemp (FRC-PD and FRC$\mathrm{DE}$, respectively), Table 1 clearly shows the superior mechanical properties of the FRC-PD composites compared to FRC-DE composites, suggesting that careful separation of the fibres from the plant does have a positive impact by retaining a higher level of performance compared to fibres that undergo processing. This agrees with work done by Thygesen et al. [12] for hemp and by Hänninen et al. [18] for flax fibre. For example, at $63.3 \mathrm{~kJ} \mathrm{~m}^{-2}$, the work of fracture (work $\mathrm{FRC}_{\mathrm{FR}}$ ) of the FRC-PD composites is $49 \%$ greater than the FRC-DE composites $\left(42.6 \mathrm{~kJ} \mathrm{~m}^{-2}\right)$. Tensile strength $\left(\sigma_{\mathrm{FRC}}\right)$ is $36 \%$ greater in the FRC-PD

Table 1 Mechanical properties of 30\% (vol\%) hemp fibre-reinforced epoxy resin composite and reference pure epoxy resin specimens produced in this work. Mean values with standard deviation in parentheses

\begin{tabular}{|c|c|c|c|c|c|c|c|}
\hline & $n$ & $\sigma_{\mathrm{FRC}}$, in $\mathrm{MPa}^{(1)}$ & $E_{\mathrm{FRC}}$, in $\mathrm{GPa}^{(1)}$ & $\varepsilon_{\mathrm{FRC}}$, in $\%^{(1)}$ & Work $_{\mathrm{FRC}}$, in $\mathrm{kJ} \mathrm{m}^{-2(2)}$ & $\sigma_{\mathrm{YP}}$, in $\mathrm{MPa}^{(3)}$ & Curve types \\
\hline FRC-REF & 5 & $46.76(8.33)$ & $1.87(0.12)$ & $4.11(1.05)$ & $30.9(13.8)$ & $34.03(3.87)$ & Nonlinear: 5 \\
\hline FRC-PD & 18 & $189.10(35.94)$ & $7.39(0.76)$ & $2.79(0.30)$ & $63.3(17.4)$ & $155.00(44.94)$ & Linear: 10 Nonlinear: 8 \\
\hline FRC-DE & 23 & $138.54(21.46)$ & $6.23(0.51)$ & $2.61(0.37)$ & $42.6(12.1)$ & $83.34(29.76)$ & Linear: 1 Nonlinear: 22 \\
\hline
\end{tabular}

\footnotetext{
${ }^{(1)}$ Related to the stress-strain curve (Fig. 4a)

${ }^{(2)}$ Calculated with the area under the load-crosshead displacement curve (Fig. 4b)

${ }^{(3)}$ Calculated with the nonlinear curves in the group
} 
composite than in the FRC-DE composite (189.10 MPa and $138.54 \mathrm{MPa}$, respectively) and Young's modulus, $E_{\mathrm{FRC}}$, follows a similar trend because it is, in this case, $19 \%$ greater in FRC-PD composite than in FRC-DE composite (7.39 GPa and $6.23 \mathrm{GPa}$, respectively). These results clearly evidence the detrimental impact that fibre processing has on the tensile properties of hemp reinforced epoxy composites. Moreover, these findings are in accordance with previous work done at the fibre bundle level in hemp [12] and flax [18, 33] that shows that fibres that undergo processing exhibit lower mechanical properties compared to fibres that do not undergo processing.

The results in Table 1 are also relevant considering that hemp fibre bundles, with larger cross sections, exhibit lower mechanical properties when compared to fibre bundles with smaller cross sections when tested in tension [12, 34, 52]. However, as Table 1 shows, FRC-DE composites, i.e. reinforced with hemp with a width of $0.20 \mathrm{~mm}$ (UR-DE; processed fibre), exhibit lower mechanical performance than the FRCPD composites, which were reinforced with hemp with a larger width, i.e. $0.72 \mathrm{~mm}$ (UR-PD; un-processed fibre); which helps explain the negative impact of fibre processing on the properties of composites reinforced with hemp.

Figure 7 shows the characteristic stress-strain curves obtained with the epoxy composites tested in this work.

Firstly, the stress-strain curve of a pure epoxy resin specimen (FRC-REF) is shown in Fig. 7a. It starts with a linear zone ( $E_{\mathrm{FRC}}$ in Fig. 7a) followed by a zone showing plastic behaviour that intersects with the $0.2 \%$ offset strain line $\left(\sigma_{\mathrm{YP}}\right.$ in Fig. $\left.7 \mathrm{a}\right)$ at the 'yield' point and continues to a maximum stress level (tensile strength; $\sigma_{\mathrm{FRC}}$ in Fig. 7a). After this point, the stress-strain curve continues in a zone where the stress decreases below the maximum stress, while strain increases, before the material fails $\left(\varepsilon_{\mathrm{FRC}}\right.$ in Fig. 7a).

The curves shown in Fig. 7 also highlight another difference between the composites reinforced with un-processed and processed fibre bundles (FRC-PD and FRC-DE). Characteristic linear and nonlinear stress-strain curves observed in the fibre-reinforced composites (both FRC-PD and FRC-DE) are shown in Fig. $7 b, c$, respectively.

Figure $7 \mathrm{~b}$ illustrates typical 'linear' behaviour, with no intersection of the $0.2 \%$-offset strain line with the stress-strain curve. In contrast, the 'nonlinear' curve shown in Fig. 7c exhibits the characteristic strain hardening behaviour observed in bast fibre-reinforced polymer matrix composites [53, 54], and the $0.2 \%$-offset strain line that intersects the stress-strain curve at a yield point $\left(\sigma_{\mathrm{YP}}\right.$ in Fig. $\left.7 \mathrm{c}\right)$. This 'nonlinear' behaviour was observed by Hughes et al. [53] and Charlet et al. [54], who studied how unidirectional flax fibre-reinforced unsaturated polyester composites, loaded in axial tension, behave. On the other hand, the glass fibre-reinforced composites tested by Hughes et al. [53] did not exhibit such nonlinear behaviour, which suggested that the nonlinearity was related to the flax fibres. Moreover, the results of Charlet et al. [54] showed that the changes in the slopes of the stress-strain response of the composites mimic that of single flax fibres tested in axial tension, suggesting that the mechanical behaviour of the fibre influences the mechanical response of the composite.

Results presented in Table 1, regarding the curve type exhibited by the epoxy composites, align with the observations of Hughes et al. [53] and Charlet et al. [54], since the predominant behaviour in the composites reinforced with processed fibre (FRC-DE) is 'nonlinear' (22 out of 23 in Table 1; Fig. 7c). On the other hand, slightly more than half the specimens in the composites reinforced with un-processed fibre (FRC-PD) exhibited 'linear' behaviour (10 out of 18; Table 1), i.e. the stress-strain curve did not cross the $0.2 \%$-offset strain line (Fig. $7 \mathrm{~b}$ ). Moreover, the values of the 'yield point' ( $\sigma_{\mathrm{YP}}$ in Table 1$)$ corroborate these findings, since the specimens in the FRC-PD (unprocessed fibre) group that behaved nonlinearly cross the $0.2 \%$-offset strain line at a mean yield stress of $155.00 \mathrm{MPa}$, whilst, for the FRC-DE (processed fibre) composites displaying nonlinear behaviour, this value is $83.34 \mathrm{MPa}$.

In addition, the epoxy composites reinforced with un-processed and processed hemp exhibited notable differences in terms of their failure characteristics. As Fig. 8 shows, for the epoxy composites reinforced with processed hemp (FRC-DE; Fig. 8d), a clean fracture surface with the fibre-reinforcement failing near to the fracture plane. The epoxy composites reinforced with un-processed fibre (FRC-PD; Fig. 8a) show that the fibre-reinforcement retains apparent structural integrity after the failure of the composite, evidenced by the splitting of the fibre bundle structure into individual fibres. The fibre-reinforcement in Fig. 8a looks as it has been pulled out 


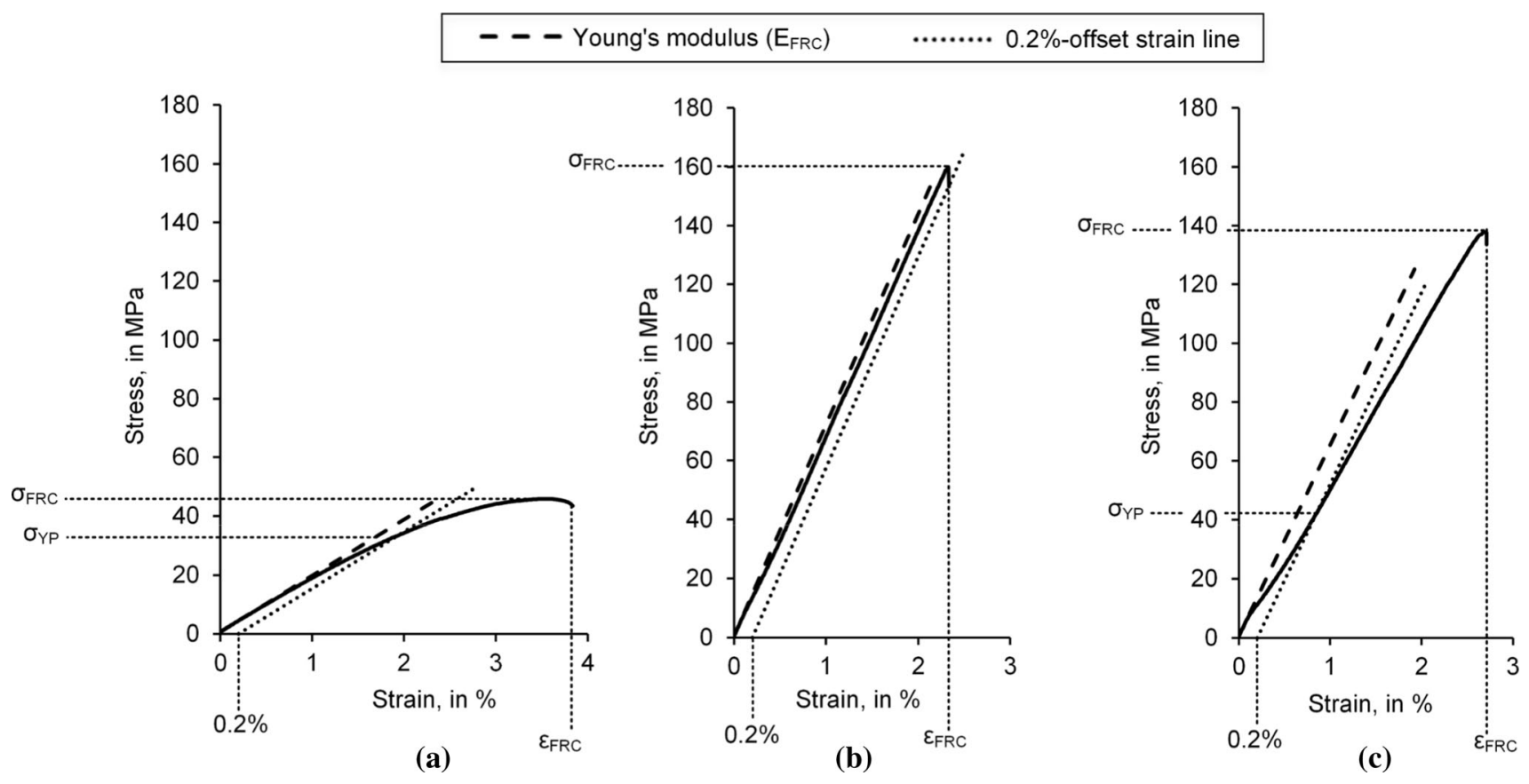

Figure 7 Characteristic stress-strain curves obtained for the epoxy resin specimens tested in this work. a pure epoxy resin specimen, b linear behaviour of a $30 \%$ (vol\%) hemp fibre- reinforced epoxy resin composite specimen, $\mathbf{c}$ nonlinear behaviour of a $30 \%$ (vol\%) hemp fibre-reinforced epoxy resin composite specimen.
FRC-PD
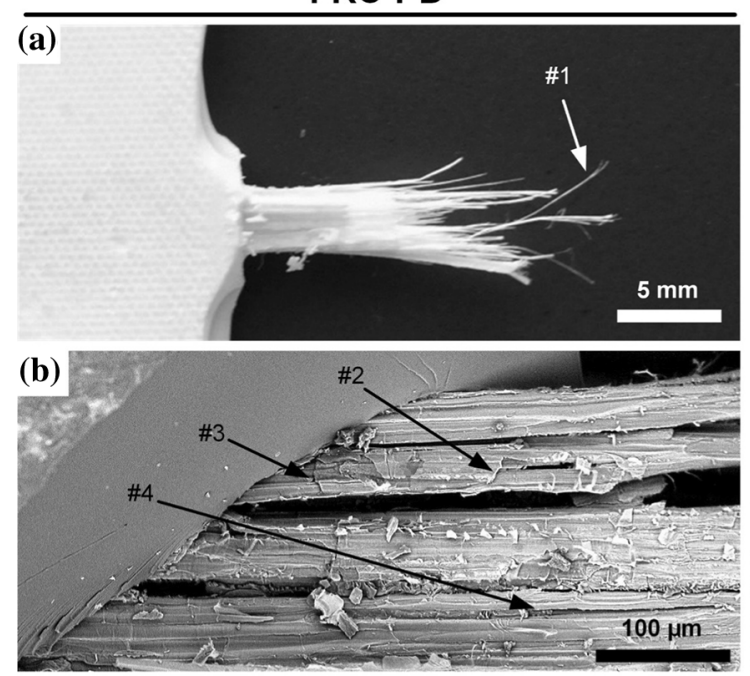

(c)

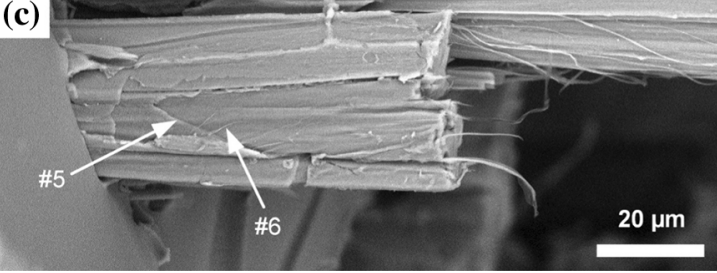

Figure 8 a, $\mathbf{b}$ and $\mathbf{c}$ : Images of fibre-reinforced epoxy composites reinforced with un-retted hemp extracted manually from the stems (FRC-PD), after failure in the tensile test. $\mathbf{d}$ and $\mathbf{e}$ : Images of fibre-

\section{FRC-DE}

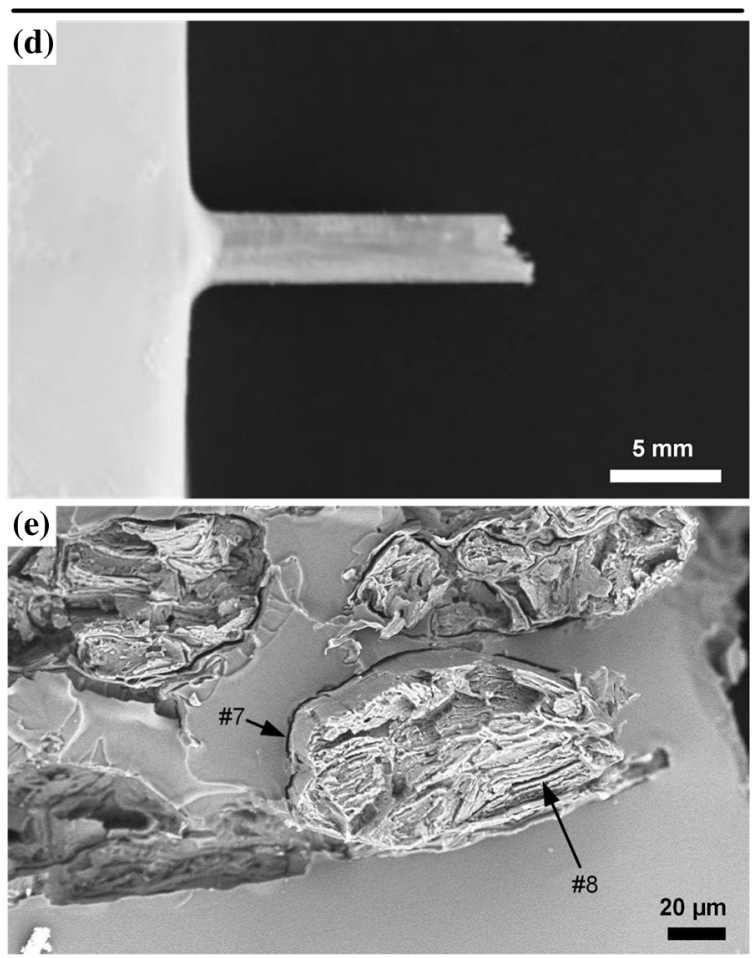

reinforced epoxy composites reinforced with un-retted, decorticated hemp (FRC-DE) after failure in the tensile test. 
of the matrix and shows what appears to be individual fibres (\#1 in Fig. 8a).

Figure $8 \mathrm{~b}$ corroborates the observations shown in Fig. 8a, since the fibre-reinforcement appears to retain a certain structural integrity. Nevertheless, some axial splitting is observed at the fibre bundle level between two adjacent fibres (\#4 in Fig. 8b) that is reminiscent of the damage reported by Rask et al. [39] in flax yarn fibre-reinforced polymer composites. Figure $8 \mathrm{~b}$ shows that in regions of the fibre-reinforcement, some of the external surface appears to have been torn off from the underlying part of the fibre (e.g. \#2 in Fig. 8b), which shows, below the tornoff tissue, what seems to be the structure of the fibre bundle. In this work, FRC-PD composites were reinforced with un-retted hemp (UR-PD fibre in Fig. 2) carefully extracted manually from the stem, which most likely had some extraneous tissue attached to the fibre bundle. Therefore, the detail presented in \#2 in Fig. $8 \mathrm{~b}$ could correspond to bark tissue removed from the fibre bundle structure when pulling the fibre-reinforcement out of the matrix.

Similarly, Fig. 8c shows the fracture surface of a FRC-PD composite specimen in which the fibre-reinforcement has been partially pulled out of the matrix. In \#5 in Fig. 8c, there is a zone that resembles the torn-off tissue characteristic presented in \#2 in Fig. 8b; however, in this case, it looks remarkably different. The torn-off tissue in \#5 (Fig. 8c) exhibits what seems to be cellulose fibrils below (\#6 in Fig. 8c) with a fibril width of $0.25 \mu \mathrm{m}(0.07 \mu \mathrm{m})$ (mean and standard deviation of three measured fibrils with five measures per fibril). This fibril width is coincident with the $0.25 \mu \mathrm{m}$ reported by Bos et al. [40] for the mesofibril structure belonging to the secondary cell wall layer, and, therefore, it might confirm that the damage presented in \#5 (Fig. 8c) corresponds to failure within the fibre cell wall, quite probably at the interface separating the primary and secondary cell walls. The weakly attached layers within the $S_{2}$ layer have been confirmed by Thygesen et al. [55], who investigated the structure of hemp fibres using SEM and transmission electron microscopy (TEM), and this was recently corroborated by Hernandez-Estrada et al. [56] who used TEM to investigate the ultrastructure of dislocations in axially sectioned hemp fibres.

On the other hand, composites reinforced with processed fibre (FRC-DE) typically exhibit clear brittle fractures across the specimen perpendicular to the loading direction (Fig. 8d), with the fibre-reinforcement failing close to the main fracture plane. Closer inspection of the fibre-reinforcement in the fracture zone shows that the fibre-reinforcement displays a concentric multilayer fibre cell wall structure (\#8 in Fig. 8e). This structure has been reported in flax fibres used as reinforcement in composites [57], as well as in hemp [55] and flax [28] after failure when tested axially in tension.

Another characteristic type of damage that the fibre-reinforcement in FRC-DE composites show is fibre-matrix debonding (\#7 in Fig. 8e). This observation corresponds with previously published works by, e.g. Hughes et al. [53], Huber and Müssig [58] and Madsen et al. [57], who reported fibre-matrix debonding in flax fibre-reinforced polymer composites. Moreover, Rask et al. [39] presented findings that show that the failure of the fibre-reinforcement starts at the dislocation, supports the hypothesis that the fracture of the epoxy composites reinforced with processed hemp studied in this work is related to the fibre dislocations.

In conclusion, if it is assumed that the fibre-matrix debonding shown in Fig. 8e is related to the presence of dislocations, the results presented in Table 1 are more understandable. Epoxy composites reinforced with un-processed hemp (FRC-PD), despite having some remaining bark tissue attached to the fibre bundle (\#2 and \#3 in Fig. 8b), should be able to withstand higher loads than composites reinforced with processed hemp (FRC-DE) due to the lack of dislocations produced during processing. On the other hand, it makes sense that epoxy composites reinforced with processed fibre (FRC-DE) would exhibit reduced properties because of the presence of dislocations in the fibres which, in addition, would result in a nonlinear stress-strain response (Table 1; Fig. 7c). Defects would weaken the fibre locally, cause local stress concentrations around the dislocation, in agreement to Hughes et al. [30], and result in failure of the fibre reinforcement at the dislocation, as noted by Rask et al. [39], exhibiting the fibre morphology shown in Fig. 8e. This event would eventually facilitate the progressive failure of the fibre reinforcement nearby and would cause, in the end, total failure of the composite at the nearby zone, exhibiting the fracture characteristics shown in Fig. 8d. 


\section{Wood-based particleboard reinforced with hemp}

Figure 9 and Table 2 show that the two sets of particleboards reinforced with un-processed and processed hemp fibre bundles (WPB-PD and WPB-DE, respectively, in Fig. 2) clearly exhibit superior mechanical properties compared to un-reinforced particleboard (WPB-REF). When the load-cross head displacement curves of un-reinforced particleboard (Fig. 9a) and fibre-reinforced particleboard (Fig. 9b) are compared, the latter displays superior three-point bending properties bending in terms of maximum load as well as crosshead displacement.

Table 2 shows that the bending modulus of elasticity $\left(\mathrm{E}_{\mathrm{WPB}}\right)$ of the three groups of reinforced and unreinforced particleboard is very similar (i.e. $1.66 \mathrm{GPa}$, 1.66 GPa and 1.63 GPa for WPB-REF, WPB-PD and WPB-DE, respectively, in Table 2). ANOVA confirmed no significant difference between these three specimen groups at a confidence level of $95 \%$. These results show that reinforcement does not provide any significant stiffening effect with the amount of fibre used in this work, as it was in the case of the work by Sam-Brew and Smith [17], who found a $32 \%$ improvement in the modulus of elasticity when wood particleboard was reinforced with unidirectional hemp fibre. This might be explained by the low amount of fibre used in the reinforcement of the particleboard. The mass ratio of fibre to particleboard was 1:185.

On the other hand, ANOVA shows significant differences between the un-reinforced particleboards
(WPB-REF) and the fibre-reinforced ones (WPB-PD and WPB-DE) in terms of bending strength $\left(\sigma_{\mathrm{WPB}}\right)$, maximum deflection and work (work $\left.\mathrm{WPB}_{\mathrm{WPB}}\right)$. As noted from Table 2, the work of fracture ( work $_{\mathrm{WPB}}$ ) of the fibre-reinforced particleboards is $293 \%$ (WPB-DE) and $308 \%$ (WPB-PD) greater than the reference value, i.e. $3.34 \mathrm{~kJ} \mathrm{~m}^{-2}, 3.47 \mathrm{~kJ} \mathrm{~m}^{-2}$ and $0.85 \mathrm{~kJ} \mathrm{~m}^{-2}$, respectively. Likewise, the bending strength $\left(\sigma_{\mathrm{WPB}}\right.$ in Table 2) of the two sets of fibre-reinforced particleboards is $75 \%$ and $70 \%$ greater (WPB-PD and WPB$\mathrm{DE}$, respectively) than the un-reinforced reference values (WPB-REF), i.e. $22.81 \mathrm{MPa}, 22.14 \mathrm{MPa}$ and $13.04 \mathrm{MPa}$, respectively. The maximum deflection (Table 2) of the fibre-reinforced particleboards show values $110 \%$ and $112 \%$ greater than the reference values (WPB-DE \& WPB-PD and WPB-REF, respectively), i.e. $3.13 \mathrm{~mm}, 3.16 \mathrm{~mm}$ and $1.49 \mathrm{~mm}$.

However, comparing the bending strength $\left(\sigma_{\mathrm{WPB}}\right)$, work (work ${ }_{\mathrm{WPB}}$ ) and maximum deflection of the two groups of particleboards reinforced with un-processed and processed hemp (WPB-PD and WPB-DE in Table 2), the respective $t$-tests showed that both sets of results are not significantly different at a confidence level of $95 \%$, which might be explained by the low amount of fibre used to reinforce each particleboard composite rendering relatively small differences between the fibres types undetectable in these tests.

Regarding the failure characteristics, the macroscale images presented in Fig. 10a, d clearly show a different fracture morphology in the particleboards reinforced with un-processed hemp (WPB-PD; Fig. 10a) compared to those reinforced with
Figure 9 Characteristic loadcross head displacement curves for particleboard tested in three-point bending. a unreinforced particleboard (WPB-REF), and $\mathbf{b}$ reinforced particleboard (WPB-PD).

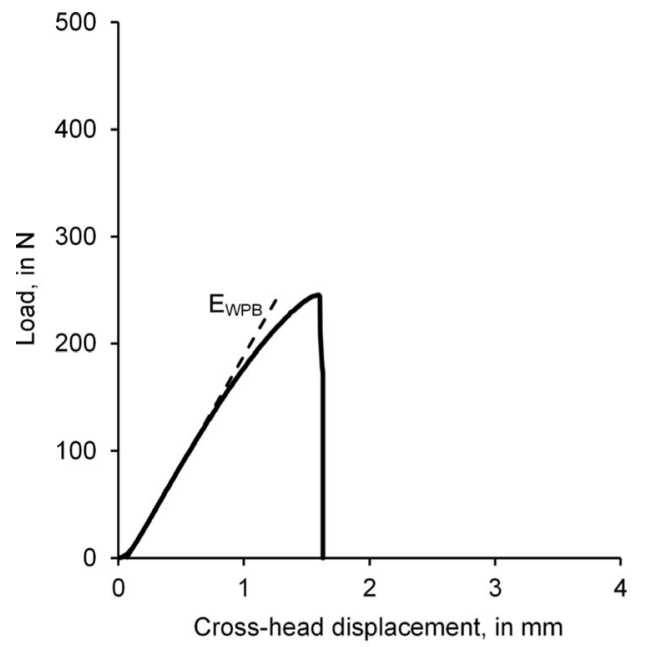

(a)

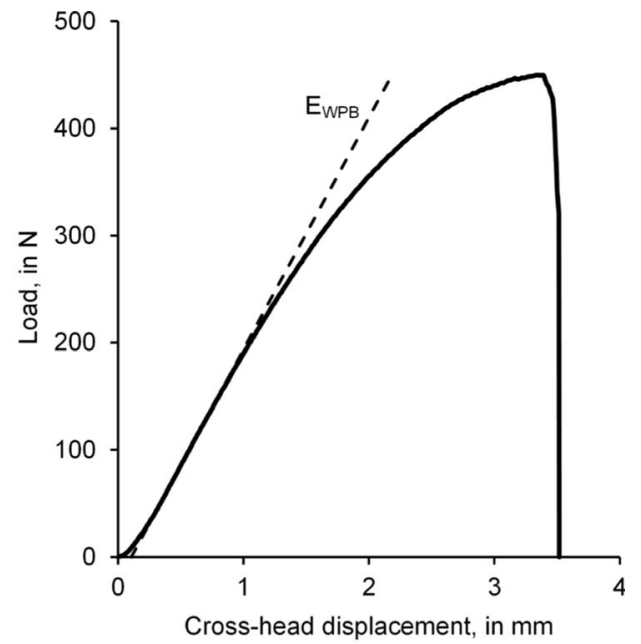

(b) 
Table 2 Mechanical properties of the wood-based particleboards produced in this work, and tested in three-point bending. Mean values with standard deviation in brackets

\begin{tabular}{llllll}
\hline & $n$ & $E_{\mathrm{WPB}}$, in GPa & $\sigma_{\mathrm{WPB}}$, in MPa & Maximum deflection, in mm & Work $_{\mathrm{WPB}}$, in $_{\mathrm{kJ} \mathrm{m}}{ }^{-2}$ \\
\hline WPB-REF & 20 & $1.66(0.08)$ & $13.04(1.09)$ & $1.49(0.13)$ & $0.85(0.13)$ \\
WPB-PD & 13 & $1.66(0.10)$ & $22.81(2.85)$ & $3.13(0.34)$ & $3.47(0.64)$ \\
WPB-DE & 15 & $1.63(0.13)$ & $22.14(1.50)$ & $3.16(0.39)$ & $3.34(0.67)$ \\
\hline
\end{tabular}

WPB-PD
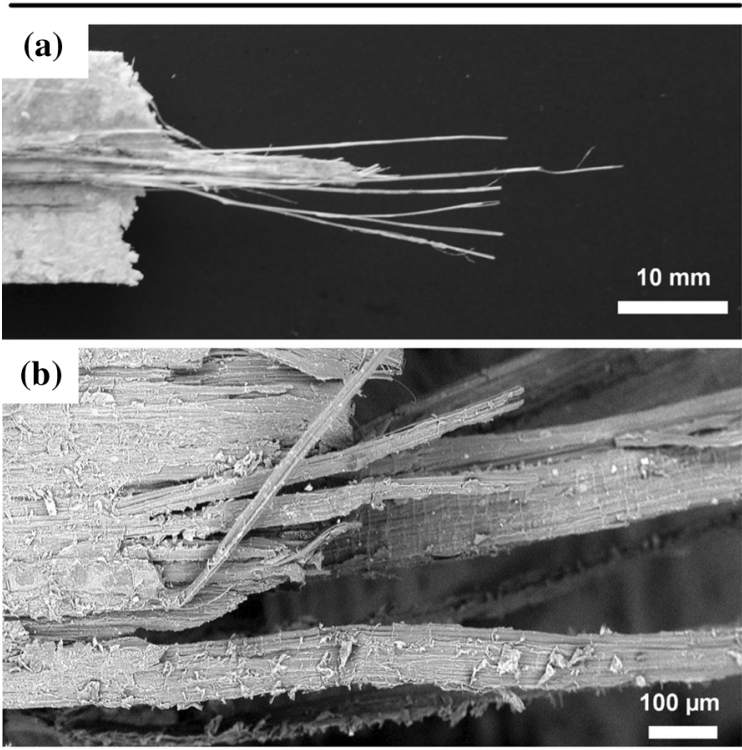

(c)

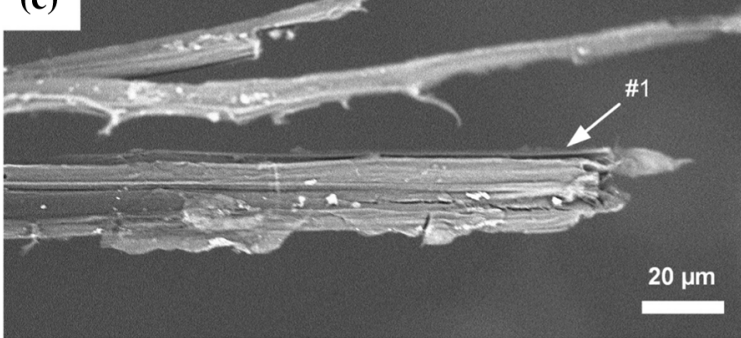

Figure 10 a, b and c: Images of wood-based particleboard specimens reinforced with dew-retted hemp prior to decortication (WPB-PD), after failure in three-point bending test. $\mathbf{d}$ and $\mathbf{e}$ :

processed hemp (WPB-DE; Fig. 10d). Figure 10a shows fibre-reinforcement with apparent structural integrity after failure of the particleboard specimens, whilst, on the other hand, Fig. 10d shows a clear cut of the fibre-reinforcement at the fracture zone. Figure $10 \mathrm{~b}$ confirms the observations of Fig. 10a and shows in detail what seems to be single fibres retaining apparent structural integrity after failure of the specimen. Moreover, Fig. 10c shows the external surface of a fibre-reinforcement that looks like it has

\section{WPB-DE}
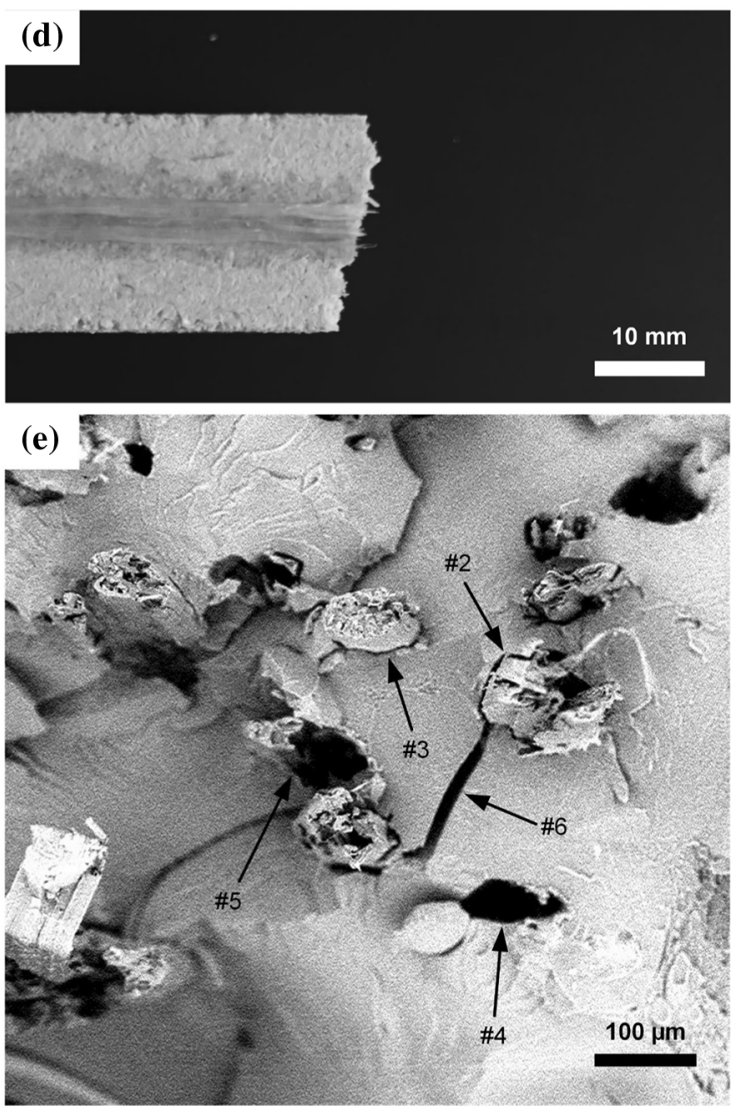

Images of wood-based particleboard specimens reinforced with dew-retted decorticated hemp (WPB-DE), after failure in threepoint bending test.

been torn from the core part of the fibre (\#1 in Fig. 10c). This characteristic is similar to the damage presented in \#5 in Fig. $8 \mathrm{c}$ as well as the characteristic damage reported by Beaugrand et al. [41] for flax fibres tested axially in tension. Feature \#1 in Fig. 10c suggests that some part of the damage would have taken place in the internal fibre structure between adjacent cell wall layers, since the fibre-reinforcement was on the tension side in the three-point bending test. 
In contrast, the characteristic failure of WPB-DE particleboards (Fig. 10d) shows that the fibre-reinforcement failed mainly in the fracture zone. Accordingly, Fig. 10e also shows that some parts of the fibre-reinforcement looked to have been pulled out of the matrix (e.g. \#4 and \#5 in Fig. 10e), in agreement to the findings of Madsen et al. [57] and Bos et al. [40] in flax fibre-reinforcement of polymer composites. Furthermore, Fig. 10e shows different fibre-matrix debonding damage in the fibre-reinforcement at the fracture zone of the composite (e.g. $\# 2$ and \#3 in Fig. 10e), which is in agreement with the results presented for epoxy resin composites (Fig. 8e). On the other hand, this fibre-matrix debonding characteristic in \#2 and \#3 in Fig. 10e could be as well attributed to a poor fibre-matrix interphase, since, e.g. the debonding characteristic shown in \#2 (Fig. 10e) seems to be the continuation of the crack shown in \#6 (Fig. 10e).

Despite showing some similarity with the epoxy composites produced in this work, particleboards reinforced with un-processed fibre do not clearly show a substantially superior mechanical performance to particleboard reinforced with processed fibre. This could be related to the fact that in this work the mass of the fibre used to reinforce every particleboard piece had a 1:185 mass ratio, when comparing both nominal masses for the fibre reinforcement and the particleboard piece. On the other hand, the results clearly show the superior performance of the fibre-reinforced particleboards (WPB$P D$ and WPB-DE) when compared to the un-reinforced particleboards (WPB-REF). This superior performance highlights the opportunity to reinforce the particleboard with natural fibre to obtain greater bending strength and suggests that such material could be used in more mechanically demanding applications, when reinforcing the bending strength with bast fibres or NFRP elements.

\section{Conclusions}

Two different types of composites were produced in this work; a fibre-reinforced epoxy resin composite and a wood-based particleboard with oriented 120-mm-long fibre bundles on the surface. Both materials were reinforced with either un-processed or processed (i.e. decorticated) hemp fibre bundles, to investigate how the fibre processing and the related fibre dislocations affect the mechanical properties of the materials. The results of this work confirm the superior behaviour of specimens reinforced with unprocessed hemp when compared to the specimens reinforced with processed hemp, especially for the epoxy composites that exhibit, for example, a work of fracture $49 \%$ greater in specimens reinforced with unprocessed hemp when compared to the composites reinforced with processed hemp. In the wood-based particleboard specimens, this relationship is less evident; however, the results obtained in this work elucidate the superior mechanical performance of the fibre-reinforced particleboards when compared to the un-reinforced particleboard. For example, particleboards reinforced with processed fibre exhibited a work of fracture $293 \%$ greater than the un-reinforced ones. Moreover, a common characteristic in both materials investigated in this work was the different failure characteristics. While epoxy composites and particleboards reinforced with processed hemp exhibit the fibre-reinforcement with a clear cut at the fracture zone, the composites reinforced with unprocessed hemp show, after the failure of the specimens, apparently structurally intact fibre reinforcement, being pulled out of the matrix. In some cases, the un-processed hemp fibre-reinforcement used in this work also shows some parts of the external fibre cell wall layers that look like they have been torn off from the fibre structure, which indicates that failure might have occurred within the fibre cell wall structure. On the other hand, epoxy composites and particleboards reinforced with processed hemp showed a clear cut at the fracture zone of the composite specimens, in some cases showing, as well, some short parts of the fibre bundles being pulled out of the matrix.

\section{Acknowledgements}

Albert Hernandez-Estrada wishes to thank the Finnish Cultural Foundation for financial support and COST Action FP1303 for supporting the STSM. Birgit Uhrlaub (HSB-City University of Applied Sciences, Bremen, Germany), and Dr Hans-Jörg Gusovius and Dr Carsten Lühr (Leibniz Institute for Agricultural Engineering and Bioeconomy ATB, Potsdam, Germany) are thanked for processing and providing the hemp. Dr Nina Graupner and Milan Kelch (HSBCity University of Applied Sciences, Bremen, 
Germany) are thanked for guidance in producing the epoxy composites and in testing the specimens. Niels Kühn (HSB-City University of Applied Sciences, Bremen, Germany) is thanked for the production of the 3D-printed moulds, which facilitated the production of the embeddings in polyurethane resin.

\section{Funding}

Open Access funding provided by Aalto University.

\section{Declarations}

Conflict of interest The authors declare that they have no conflict of interest.

Open Access This article is licensed under a Creative Commons Attribution 4.0 International License, which permits use, sharing, adaptation, distribution and reproduction in any medium or format, as long as you give appropriate credit to the original author(s) and the source, provide a link to the Creative Commons licence, and indicate if changes were made. The images or other third party material in this article are included in the article's Creative Commons licence, unless indicated otherwise in a credit line to the material. If material is not included in the article's Creative Commons licence and your intended use is not permitted by statutory regulation or exceeds the permitted use, you will need to obtain permission directly from the copyright holder. To view a copy of this licence, visit http://creativecommons.org/licen ses/by $/ 4.0 /$.

\section{References}

[1] Pickering KL, Aruan Efendy MG, Le TM (2016) A review of recent developments in natural fibre composites and their mechanical performance. Compos A 83:98-112. https:/doi. org/10.1016/j.compositesa.2015.08.038

[2] Kumar R, Haq MIU, Raina A, Anand A (2019) Industrial applications of natural fibre-reinforced polymer composites challenges and opportunities. Int J Sustain Eng 12:212-220. https://doi.org/10.1080/19397038.2018.1538267

[3] Ramesh M (2019) Flax (Linum usitatissimum L.) fibre reinforced polymer composite materials: a review on preparation, properties and prospects. Prog Mater Sci 102:109-166. https://doi.org/10.1016/j.pmatsci.2018.12.004
[4] Müssig J, Amaducci S, Bourmaud A et al (2020) Transdisciplinary top-down review of hemp fibre composites: From an advanced product design to crop variety selection. Compos Part C: Open Access 2:100010. https://doi.org/10. 1016/j.jcomc.2020.100010

[5] Meredith J, Ebsworth R, Coles SR et al (2012) Natural fibre composite energy absorption structures. Compos Sci Technol 72:211-217. https://doi.org/10.1016/j.compscitech.2011.11. 004

[6] Wambua P, Ivens J, Verpoest I (2003) Natural fibres: can they replace glass in fibre reinforced plastics? Compos Sci Technol 63:1259-1264. https://doi.org/10.1016/S0266-3538 (03)00096-4

[7] Gomina M (2012) VIII - Flax \& hemp composite applications. Flax and hemp fibres: a natural solution for the composite industry. JEC Composites and CELC, Paris, France, pp 141-162

[8] Pil L, Bensadoun F, Pariset J, Verpoest I (2016) Why are designers fascinated by flax and hemp fibre composites? Compos A 83:193-205. https://doi.org/10.1016/j.composite sa.2015.11.004

[9] Pacheco-Torgal F, Jalali S (2011) Cementitious building materials reinforced with vegetable fibres: a review. Constr Build Mater 25:575-581. https://doi.org/10.1016/j.conbuild mat.2010.07.024

[10] Merta I, Tschegg EK (2013) Fracture energy of natural fibre reinforced concrete. Constr Build Mater 40:991-997. http s://doi.org/10.1016/j.conbuildmat.2012.11.060

[11] Dalmay P, Smith A, Chotard T et al (2010) Properties of cellulosic fibre reinforced plaster: influence of hemp or flax fibres on the properties of set gypsum. J Mater Sci 45:793-803. https://doi.org/10.1007/s10853-009-4002-x

[12] Thygesen A, Madsen B, Bjerre AB, Lilholt H (2011) Cellulosic fibers: effect of processing on fiber Bundle strength. J Nat Fibers 8:161-175. https://doi.org/10.1080/15440478. 2011.602236

[13] Hughes M (2012) Defects in natural fibres: their origin, characteristics and implications for natural fibre-reinforced composites. J Mater Sci 47:599-609. https://doi.org/10.100 7/s10853-011-6025-3

[14] Müssig J, Hughes M (2012) II - Reinforcements: fibres. Flax and hemp fibres: a natural solution for the composite industry. JEC Composites and CELC, Paris, France, pp 39-60

[15] Baley C, Bourmaud A, Davies P (2021) Eighty years of composites reinforced by flax fibres: a historical review. Compos A 144:106333. https://doi.org/10.1016/j.composite sa.2021.106333 
[16] Borri A, Corradi M, Speranzini E (2013) Reinforcement of wood with natural fibers. Compos B Eng 53:1-8. https://doi. org/10.1016/j.compositesb.2013.04.039

[17] Sam-Brew S, Smith GD (2015) Flax and Hemp fiber-reinforced particleboard. Ind Crops Prod 77:940-948. https://d oi.org/10.1016/j.indcrop.2015.09.079

[18] Hänninen T, Michud A, Hughes M (2011) Kink bands in bast fibres and their effects on mechanical properties. Plast Rubber Compos 40:307-310. https://doi.org/10.1179/17432 89810Y.0000000020

[19] Bourmaud A, Beaugrand J, Shah DU et al (2018) Towards the design of high-performance plant fibre composites. Prog Mater Sci 97:347-408. https://doi.org/10.1016/j.pmatsci.20 18.05.005

[20] Thygesen LG (2011) The effects of growth conditions and of processing into yarn on dislocations in hemp fibres. J Mater Sci 46:2135-2139. https://doi.org/10.1007/s10853-010-504 $9-4$

[21] Hänninen T, Thygesen A, Mehmood S et al (2012) Mechanical processing of bast fibres: the occurrence of damage and its effect on fibre structure. Ind Crops Prod 39:7-11. https://doi.org/10.1016/j.indcrop.2012.01.025

[22] Melelli A, Durand S, Arnould O et al (2021) Extensive investigation of the ultrastructure of kink-bands in flax fibres. Ind Crops Prod 164:113368. https://doi.org/10.1016/j. indcrop.2021.113368

[23] Thygesen LG, Eder M, Burgert I (2007) Dislocations in single hemp fibres - investigations into the relationship of structural distortions and tensile properties at the cell wall level. J Mater Sci 42:558-564. https://doi.org/10.1007/s108 53-006-1113-5

[24] Thygesen LG, Gierlinger N (2013) The molecular structure within dislocations in Cannabis sativa fibres studied by polarised Raman microspectroscopy. J Struct Biol 182:219-225. https://doi.org/10.1016/j.jsb.2013.03.010

[25] Thygesen LG, Hoffmeyer P (2005) Image analysis for the quantification of dislocations in hemp fibres. Ind Crops Prod 21:173-184. https://doi.org/10.1016/j.indcrop.2004.03.001

[26] Dinwoodie JM (1968) Failure in timber. 1. Microscopic changes in cell-wall structure associated with compression failure. J Ins Wood Sci 21:37-53

[27] Nyholm K, Ander P, Bardage S, Geoffrey D (2001) Dislocations in pulp fibres - their origin, characteristics and importance - a review. Nord Pulp Pap Res J 16:376-384. h ttps://doi.org/10.3183/npprj-2001-16-04-p376-384

[28] Bos HL, Van Den Oever MJA, Peters OCJJ (2002) Tensile and compressive properties of flax fibres for natural fibre reinforced composites. J Mater Sci 37:1683-1692. https://d oi.org/10.1023/A:1014925621252
[29] Thygesen LG, Bilde-Sørensen JB, Hoffmeyer P (2006) Visualisation of dislocations in hemp fibres: a comparison between scanning electron microscopy (SEM) and polarized light microscopy (PLM). Ind Crops Prod 24:181-185. http s://doi.org/10.1016/j.indcrop.2006.03.009

[30] Hughes M, Sèbe G, Hague J et al (2000) An investigation into the effects of micro-compressive defects on interphase behaviour in hemp-epoxy composites using half-fringe photoelasticity. Compos Interfaces 7:13-29. https://doi.org/ 10.1163/156855400300183551

[31] Hernandez-Estrada A, Gusovius H-J, Müssig J, Hughes M (2016) Assessing the susceptibility of hemp fibre to the formation of dislocations during processing. Ind Crops Prod 85:382-388. https://doi.org/10.1016/j.indcrop.2016.01.006

[32] Baley C (2004) Influence of kink bands on the tensile strength of flax fibers. J Mater Sci 39:331-334. https://doi. org/10.1023/B:JMSC.0000007768.63055.ae

[33] Aslan M, Chinga-Carrasco G, Sørensen BF, Madsen B (2011) Strength variability of single flax fibres. J Mater Sci 46:6344-6354. https://doi.org/10.1007/s10853-011-5581-x

[34] Duval A, Bourmaud A, Augier L, Baley C (2011) Influence of the sampling area of the stem on the mechanical properties of hemp fibers. Mater Lett 65:797-800. https://doi.org/10. 1016/j.matlet.2010.11.053

[35] Placet V, Cissé O, Lamine Boubakar M (2014) Nonlinear tensile behaviour of elementary hemp fibres. Part I: investigation of the possible origins using repeated progressive loading with in situ microscopic observations. Compos A 56:319-327. https://doi.org/10.1016/j.compositesa.2012.11. 019

[36] Baley C (2002) Analysis of the flax fibres tensile behaviour and analysis of the tensile stiffness increase. Compos A 33:939-948. https://doi.org/10.1016/S1359-835X(02)000404

[37] Charlet K, Baley C, Morvan C et al (2007) Characteristics of Hermès flax fibres as a function of their location in the stem and properties of the derived unidirectional composites. Compos A 38:1912-1921. https://doi.org/10.1016/j.compo sitesa.2007.03.006

[3] Eichhorn SJ, Young RJ (2003) Deformation micromechanics of natural cellulose fibre networks and composites. Compos Sci Technol 63:1225-1230. https://doi.org/10.1016/S0266-3 538(03)00091-5

[39] Rask M, Madsen B, Sørensen BF et al (2012) In situ observations of microscale damage evolution in unidirectional natural fibre composites. Compos A 43:1639-1649. h ttps://doi.org/10.1016/j.compositesa.2012.02.007

[40] Bos HL, Müssig J, van den Oever MJA (2006) Mechanical properties of short-flax-fibre reinforced compounds. Compos 
A 37:1591-1604. https://doi.org/10.1016/j.compositesa.200 5.10 .011

[41] Beaugrand J, Guessasma S, Maigret J-E (2017) Damage mechanisms in defected natural fibers. Sci Rep 7:14041. h ttps://doi.org/10.1038/s41598-017-14514-6

[42] Wehsener J, Weser T, Haller P et al (2014) Textile reinforcement of multidimensional formable wood. Eur J Wood Prod 72:463-475. https://doi.org/10.1007/s00107-014-07993

[43] de Barros Filho RM, Mendes LM, Novack KM et al (2011) Hybrid chipboard panels based on sugarcane bagasse, urea formaldehyde and melamine formaldehyde resin. Ind Crops Prod 33:369-373. https://doi.org/10.1016/j.indcrop.2010.11. 007

[44] André A, Johnsson H (2010) Flax fiber-reinforced gluedlaminated Timber in tension perpendicular to the grain: experimental study and probabilistic analysis. J Mater Civ Eng 22:827-835. https://doi.org/10.1061/(ASCE)MT.19435533.0000070

[45] de la Rosa GP, Escamilla AC, Nieves González García M (2013) Bending reinforcement of timber beams with composite carbon fiber and basalt fiber materials. Compos B Eng 55:528-536. https://doi.org/10.1016/j.compositesb.2013.07. 016

[46] Wang S, Gusovius H-J, Lühr C et al (2018) Assessment system to characterise and compare different hemp varieties based on a developed lab-scaled decortication system. Ind Crops Prod 117:159-168. https://doi.org/10.1016/j.indcrop. 2018.02.083

[47] Müssig J, Fischer H, Graupner N, Drieling A (2010) Testing methods for measuring physical and mechanical fibre properties (plant and animal fibres). In: Müssig J (ed) Industrial applications of natural fibres: structure, properties and technical applications. Wiley, Chichester, United Kingdom, pp 269-310

[48] Shah DU (2014) Natural fibre composites: comprehensive ashby-type materials selection charts. Mater Des 62:21-31. h ttps://doi.org/10.1016/j.matdes.2014.05.002

[49] EN 310 (1993) Wood-based panels - Determination of modulus of elasticity in bending and of bending strength. English version. Brussels, Belgium.
[50] Hull D, Clyne TW (1996) An introduction to composite materials, 2nd edn. Cambridge University Press

[51] Gibson LJ, Ashby MF (1997) Cellular solids: structure and properties, 2nd edn. Cambridge University Press, Cambridge

[52] Placet V, Trivaudey F, Cisse O et al (2012) Diameter dependence of the apparent tensile modulus of hemp fibres: A morphological, structural or ultrastructural effect? Compos A 43:275-287. https://doi.org/10.1016/j.compositesa.2011.1 0.019

[53] Hughes M, Carpenter J, Hill C (2007) Deformation and fracture behaviour of flax fibre reinforced thermosetting polymer matrix composites. J Mater Sci 42:2499-2511. h ttps://doi.org/10.1007/s10853-006-1027-2

[54] Charlet K, Jernot J-P, Gomina M et al (2010) Mechanical properties of flax fibers and of the derived unidirectional composites. J Compos Mater 44:2887-2896. https://doi.org/ $10.1177 / 0021998310369579$

[55] Thygesen A, Daniel G, Lilholt H, Thomsen AB (2006) Hemp fiber microstructure and use of fungal defibration to obtain fibers for composite materials. J Nat Fibers 2:19-37. h ttps://doi.org/10.1300/J395v02n04_02

[56] Hernandez-Estrada A, Reza M, Hughes M (2020) The structure of dislocations in hemp (Cannabis sativa L.) fibres and implications for mechanical behaviour. BioResources 15:2579-2595. https://doi.org/10.15376/biores.15.2.25792595

[57] Madsen B, Aslan M, Lilholt H (2016) Fractographic observations of the microstructural characteristics of flax fibre composites. Compos Sci Technol 123:151-162. https://doi. org/10.1016/j.compscitech.2015.12.003

[58] Huber T, Müssig J (2008) Fibre matrix adhesion of natural fibres cotton, flax and hemp in polymeric matrices analyzed with the single fibre fragmentation test. Compos Interfaces 15:335-349. https://doi.org/10.1163/156855408783810948

Publisher's Note Springer Nature remains neutral with regard to jurisdictional claims in published maps and institutional affiliations. 